\title{
ВИЗУАЛИЗАЦИЯ МОЛЕКУЛЯРНО-ХИМИЧЕСКОГО ВЗАИМОДЕЙСТВИЯ МАТЕРИАЛА, БИОКОМПОЗИТА И ТКАНИ ЗУБА НА ОСНОВЕ СИНХРОТРОННОЙ ИК-МИКРОСПЕКТРОСКОПИИ
}

\author{
Д. Л. Голощапов ${ }^{1}$, В. М. Кашкаров ${ }^{1}$, Ю. А. Ипполитов², И. Ю. Ипполитов², Jitraporn Vongsvivut ${ }^{3}$, П. В. Середин ${ }^{1}$
}

${ }^{1}$ Воронежский государственный университет, Воронеж, Россия

${ }^{2}$ Воронежский государственный медицинский университет имени Н. Н. Бурденко, Россия

З Австралийский синхротрон, Мельбурн, Австралия

\begin{abstract}
В реставрационной стоматологии остается актуальной проблема низкого сродства композиционных материалов с нативной твердой тканью зуба. Целью работы было исследовать молекулярно-химические особенности формирования интерфейса стоматологический материал - биомиметический буферный слой - твердая ткань зуба человека. С применением метода молекулярной многомерной ИК-визуализации на 7 плоскопараллельных сегментах образцов был выполнен анализ участка интерфейса здоровая твердая ткань (эмаль/дентин) - биомиметический переходной слой - стоматологический материал/адгезивный, созданный с использованием нового поколения биомиметических материалов, воспроизводящих минералорганический комплекс эмали и дентина зубов человека, с нативными твердыми тканями зуба человека и стоматологическим цементом. Данные спектральной молекулярной визуализации, полученные на основе синхротронного ИК-картирования интенсивности функциональных молекулярных групп, позволили нам обнаружить и визуализировать различия между здоровой тканью, стоматологическим материалом и биомиметическим переходным слоем в межфазных областях (интерфейсах), а также определить локализацию и концентрацию функциональных групп, отвечающих процессам интеграции биомиметического композита и нативной твердой ткани зубов человека. Показано, что разработанная нами биомиметическая система на основе нанокристаллического карбонат-замещенного гидроксиапатита кальция, полученного из биогенного источника кальция и комплекса основных полярных аминокислот, соответствующих органоминеральному комплексу зубов человека, способна образовывать функциональную связь с твердой тканью зуба человека.
\end{abstract}

Ключевые слова: биомиметические материалы, нативная твердая ткань зуба человека, ИК-микроспектроскопия, синхротронное излучение Финансирование: исследование выполнено при поддержке гранта Российского Научного Фонда № 16-15-00003.

Благодарности: часть этого исследования была проведена с использованием канала Инфракрасной микроскопии (IRM) на Австралийском синхротроне.

Информация о вкладе авторов: Д. Л. Голощапов - планирование исследования, анализ литературы; сбор, анализ и интерпретация данных; В. М. Кашкаров - сбор, анализ, интерпретация данных; Ю. А. Ипполитов - планирование исследования, подготовка образцов, сбор и анализ данных; И. Ю. Ипполитов - подготовка образцов; Jitraporn Vongsvivut - проведение эксперимента; П. В. Середин - планирование исследования, анализ литературы, сбор, анализ, интерпретация данных, проведение эксперимента.

Соблюдение этических стандартов: исследование одобрено этической комиссией Воронежского государственного университета (протокол № 2019/3/1 от 04 марта 2019 г.).

$\varnothing$ Для корреспонденции: Павел Владимирович Середин

Университетская пл., 1, г. Воронеж, 394018; раul@phys.vsu.ru

Статья получена: 18.07.2019 Статья принята к печати: 31.07.2019 Опубликована онлайн: 01.08.2019

DOI: $10.24075 /$ vrgmu.2019.047

\section{SYNCHROTRON IR-MICROSPECTROSCOPY-BASED VISUALIZATION OF MOLECULAR AND CHEMICAL INTERACTIONS BETWEEN DENTAL CEMENT, BIOMIMETIC COMPOSITE AND NATIVE DENTAL TISSUE}

Goloshchapov DL ${ }^{1}$, Kashkarov VM¹, Ippolitov YuA ${ }^{2}$, Ippolitov IYu², Jitraporn Vongsvivut ${ }^{3}$, Seredin $\mathrm{PV}^{1}{ }^{\otimes}$

${ }^{1}$ Voronezh State University, Voronezh, Russia

2 Burdenko Voronezh State Medical University, Voronezh, Russia

${ }^{3}$ Australian Synchrotron, Melbourne, Australia

The low affinity of composite materials for the hard tissue of human teeth poses a challenge to restorative dentists. This study was undertaken to explore molecular and chemical characteristics of the interface between the dental cement, the buffer layer formed from a next generation biomimetic material that mimics the organic mineral composition of human enamel and dentin, and the intact native hard dental tissue. Seven plane-parallel dental slices were analyzed using synchrotron IR microspectroscopy. The obtained absorption spectra of functional molecular groups were organized into cluster maps. This allowed us to identify the intact tissue, the adhesive agent and the biomimetic layer at their interface and to localize and measure concentrations of functional groups involved in the integration of the biomimetic composite into the hard tissue of the human tooth. The proposed biomimetic material is based on nanocrystal carbonate-substituted calcium hydroxyapatite synthesized from a biogenic calcium source and a complex of basic polar amino acids copying the composition of the human tooth and can form a functional bond with hard dental tissue.

Keywords: biomimetic materials, native human tooth hard tissue, IR microspectroscopy, synchrotron radiation

Funding: the study was supported by the Russian Science Foundation (Grant 16-15-00003).

Acknowledgment: IR microspectroscopy was conducted at the Australian Synchrotron.

Author contribution: Goloshchapov DL planned the study, analyzed the literature, collected and interpreted the obtained data; Kashkarov VM collected, analyzed and interpreted the obtained data; Ippolitov YuA planned the study, prepared the samples, collected and analyzed the data; Ippolitov IYu prepared the samples; Jitraporn Vongsvivut conducted IR microspectroscopy; Seredin PV planned the study, analyzed the literature, collected, analyzed and interpreted the obtained data, and conducted IR microspectroscopy.

Compliance with ethical standards: the study was approved by the Ethics Committee of Voronezh State University (Protocol № 2019/3/1 dated March 4, 2019).

$\bowtie$ Correspondence should be addressed: Pavel V. Seredin Universitetskaya pl.1, Voronezh, 394018; paul@phys.vsu.ru

Received: 18.07.2019 Accepted: 31.07.2019 Published online: 01.08.2019

DOI: 10.24075/brsmu.2019.047 
Современные композиционные материалы и бонды, применяемые в реставрационной стоматологии, несмотря на высокие показатели адгезии и прочности имеют низкое сродство с нативной твердой тканью зуба по химическому составу и морфологической организации [1, 2]. Несоответствие по физико-химическим характеристикам искусственных материалов эмали и дентину зубов инициирует поиск новых композиционных соединений для реставрационной стоматологии [2, 3]. Одновременно с решением этой задачи ведется активный поиск способов улучшения интерфейса между используемыми стоматологическими материалами и твердой тканью зуба за счет новых бондинговых систем и буферных слоев, имеющих гибридный состав и позволяющих повысить долговечность реставрации [3-5]. Актуальными вопросами здесь становятся способы формирования химической связи композит/бонд/нативные ткани зуба [6].

Наилучшим решением задач формирования качественного интерфейса синтетический материалэмаль/дентин стало создание биомиметического композита, имитирующего состав, структуру (в том числе наноструктуру) твердых тканей зуба [7-9]. Хорошо известно, что введение в состав биокомпозита аналога апатита эмали - нанокристаллического гидроксиапатита кальция (ГАП) с различной десектной структурой позволяет улучшить интеграцию синтетических материалов $[5,10]$. В то же время включение в состав биокомпозитов ряда полярных аминокислот эмалевого матрикса [11-14] позволяет создать имитацию биомиметическим материалом конкретного типа участка эмали или дентина зуба человека и улучшить адгезивные и прочностные характеристики $[12,15]$.

В свою очередь, оценка интеграции бонда с тканями зубов, а также анализ формирования интерфейса адгезив/ эмаль, адгезив/дентин могут быть проведены комплексом методов, среди которых выделяют инфракрасную Фурье спектроскопию (FTIR). Данный неразрушающий метод позволяет изучить молекулярное строение и тонкие структурные свойства объектов биологического происхождения на основе анализа присутствующих в ИК-спектрах молекулярных колебательных полос, специфичных для конкретного химического вещества [16]. С его помощью можно исследовать механизмы молекулярных превращений в биомиметических материалах [17, 18], стоматологических адгезивах [19], получить обширные и разнообразные сведения о молекулярном составе тканей зубов человека [6] и регистрировать новообразованные минеральные фазы [20]. Одновременно с этим включение в измерительную схему микроскопа, а также использование источника синхротронного излучения при исследовании биологических объектов позволяют собрать большие массивы спектров с микрообласти образца [17]. На основе собранного набора спектров появляется возможность сформировать ИК-микроспектроскопическое изображение объекта, одновременно богатое различной информацией о молекулярных связях в составе образца и их пространственном распределении.

Целью работы стало исследование молекулярнохимических особенностей формирования интерфейса стоматологический материал - биомиметический буферный слой - твердая ткань зуба человека на основе многомерной визуализации данных синхротронной ИКмикроспектроскопии.

\section{МАТЕРИАЛЫ И МЕТОДЫ}

\section{Подготовка материалов}

Для получения биомиметических модельных материалов использовали описанную [21] родственную систему, содержащую: гиалуроновую кислоту (0,01-0,05 wt. \%), L-гистидин (0,01-0,2 wt. \%), L-лизин гидрохлорид (0,05-0,4 wt. \%), L-аргинин гидрохлорид (0,2-1,6 wt. \%), а также метиловый эфир этиленгликоля (30-85 wt. \%), диглицидилдиметакрилат (1-15 wt. \%), уретандиметакрилат (1-15 wt. \%), спирт этиловый (2-20 wt. \%) и воду (остальное). Выполненное исследование оптических и эмиссионных свойств предложенного биокомпозита, содержащего перечисленные аминокислоты, показало сродство свойств этого материала со свойствами, проявляемыми нативной эмалью и дентином [22]. Для формирования высокотропной к нативным тканям зуба среды в данную систему был добавлен синтетический карбонат-замещенный гидроксиапатит кальция (КГАП) в соотношении 1 мл смеси - 0,01гКГАП, соответствующий по совокупному ряду характеристик апатиту эмали и дентина зуба человека [20].

Для фиксации описанной буферной системы использовали универсальный адгезив для биоактивной бондинговой системы, эффективно связывающийся с разработанными коммерческими материалами [23]. В данный универсальный адгезив для улучшения тропности добавили полученный в данной работе КГАП в соотношении 1 мл адгезива - 0,01г КГАП. Смешивание компонента ГАП с составляющими буферной системы и адгезива осуществляли с использованием ультразвукового гомогенизатора QSonica 55 (QSonica; CША) в течение 30 с.

Интеграцию буферных слоев на основе биокомпозиционных материалов изучали на образцах зубов, удаленных у пациентов в возрасте 18-45 лет по ортодонтическим показаниям. Препарирование зубов и нанесение биомиметической буферной системь выполняли по следующей схеме.

На первом этапе проводили препарирование эмали и дентина с помощью микромоторного воздушного наконечника при скорости вращения стального шаровидного бора из легированной вольфрамванадиевой стали 4000 об./мин и водяным охлаждением для предотвращения перегрева зубного матрикса. Формирование полости под пломбу осуществляли до дентина с доводкой при малой скорости вращения. Сформированную полость промывали и высушивали потоком воздуха от компрессора.

На втором этапе осуществляли травление эмали в течение 60 с, используя гель для травления эмали на основе 37\%-й фосфорной кислоты, с последующим ополаскиванием водой и сушкой потоком воздуха. Далее производили обработку дентина с использованием дентинкондиционера [21] на основе смеси гиалуроновой кислоты (0,01-0,05 wt. \%), L-гистидина (0,01-0,2 wt. \%), L-лизина гидрохлорида (0,05-0,4 wt. \%), L-аргинина гидрохлорида (0,2-1,6 wt. \%), в течение 20-30 c, после чего осуществляи сушку поверхности полости.

На третьем этапе полученную в данной работе биокомпозиционную буферную систему равномерно распределяли в стенки сформированной полости и после 20 с высушивали с помощью воздушного компрессора. На подготовленную таким образом полость на поверхность буферного слоя наносили универсальный 
светоотверждаемый адгезив, содержащий КГАП, который подвергали последующей предварительной фотополимеризации в течение 20 c.

На заключительном четвертом этапе по истечении 1 мин на сформированный биомиметический буферный слой наносили коммерческий компомерный реставрационный материал, содержащий компоненты адгезива.

Учитывая требования методики исследования (ИК-микроспектроскопии) к геометрии образцов, мы подготовили плоскопараллельные сегменты образцов отреставрированных зубов, аналогично тем, которые были исследованы ранее [24].

В работе было изучено 7 плоскопараллельных сегментов образцов, приготовленных непосредственно перед исследованием.

\section{Методика исследования образцов}

Молекулярный состав образцов, а также области интерфейса стоматологический материал биомиметический буферный слой - нативная твердая ткань зуба человека изучали с использованием синхротронной ИК-микроспектроскопии, с применением методики нарушенного полного внутреннего отражения (НПВО). Исследование проводили на оборудовании канала инфракрасной микроспектроскопии (IRM) Австралийского синхротрона (Мельбурн, Австралия), имеющего в своем составе ИК-микроскоп Нyperion 3000 (Bruker; США) и приставку НПВО с германиевой призмой (Мельбурн, Австралия) [17]. На рис. 1А, Б выделенной прямоугольной областью показано изображение исследуемого участка интерфейса, от которого были получены ИК-спектры поглощения в области от 3800-700 см$^{-1}$ (рис. 1В).
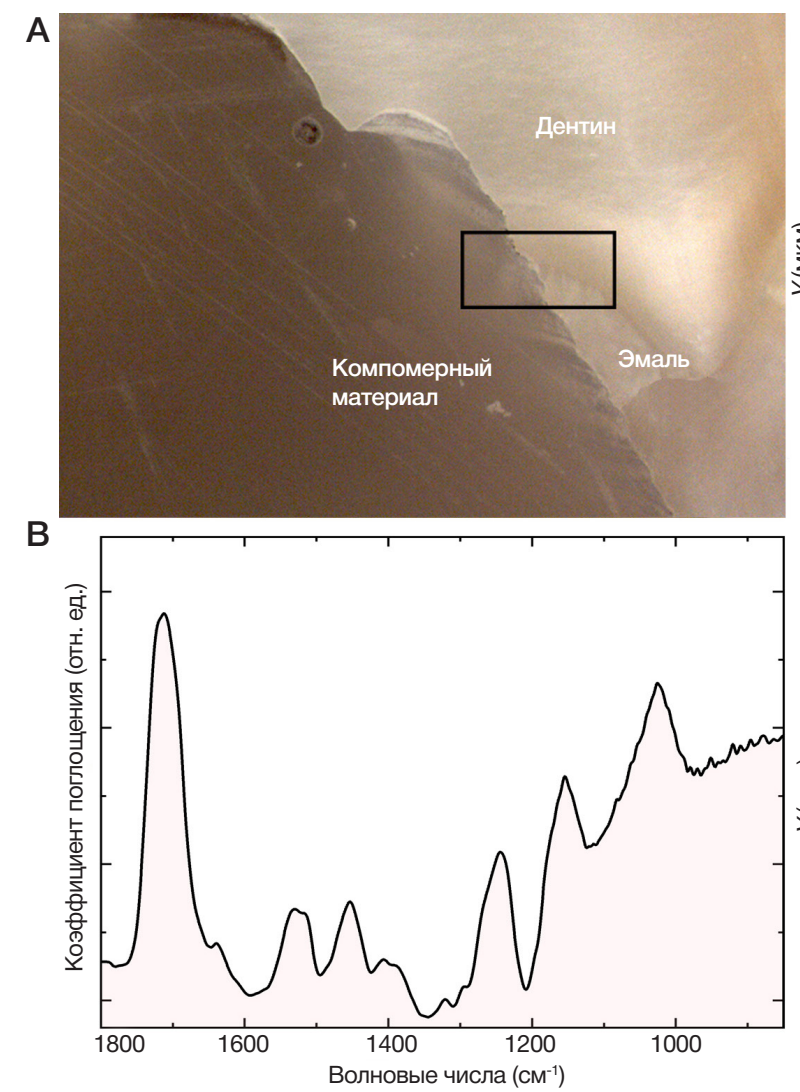

Рис. 1. Оптическое изображение плоскопараллельного сегмента исследуемого зуба человека с межфазной границы стоматологический материал/ биокомпозит/эмаль/дентин (А) с участком 100×200 мкм; 20× оптическое изображение данной области гетеросазной границы (Б); типичный ИК-спектр поглощения из области межфазной границы (В); ИК-карта общего поглощения, составленная на основе массива данных ИК-микроспектроскопии (Г)
С использованием возможностей ИК-микроскопа и программного комплекса OPUS 7.5 (Bruker; CША) на участке образца размером 100×100 мкм (рис. 1Б) с шагом 2 мкм получили совокупность ИК-спектров (выполнили молекулярное картирование), в результате чего построили одномерные ИК-изображения (ИК-карты) на основе цветового кодирования интенсивностей полос поглощения ИК-спектров (рис. 1Г). Синим цветом закодирована самая низкая интенсивность поглощения молекулярной группой, выбранной для картирования, в то время как красным показана самая высокая. Данные карты показывают распределение интенсивности молекулярной группы, а следовательно, ее концентрации в конкретной точке исследуемого образца.

\section{РЕЗУЛЬТАТЫ ИССЛЕДОВАНИЯ}

В ходе исследования участка межфазной границы (рис. 1Б) между светоотверждаемым стоматологическим материалом, биомиметическим композитом, а также эмалью и дентином зуба был идентифицирован набор основных колебательных мод в ИК-спектре (рис. 1В), которые могут выступать в роли спектроскопических сигнатур, отвечающих веществам, присутствующим в области интеграции.

Наиболее интенсивная полоса в ИК-спектре, расположенная в области 1163-981 см-1, принадлежит к группе $\mathrm{PO}_{4}$ минеральной составляющей апатита эмали и дентина [22]. Следующая группа полос в ИК-спектре от 1700 до $1100 \mathrm{~cm}^{-1}$ относится к колебаниям протеинов, входящих в состав органической составляющей эмали/дентина, а также соединениям биомиметического композита (см. методику подготовки материалов). Наиболее интенсивные

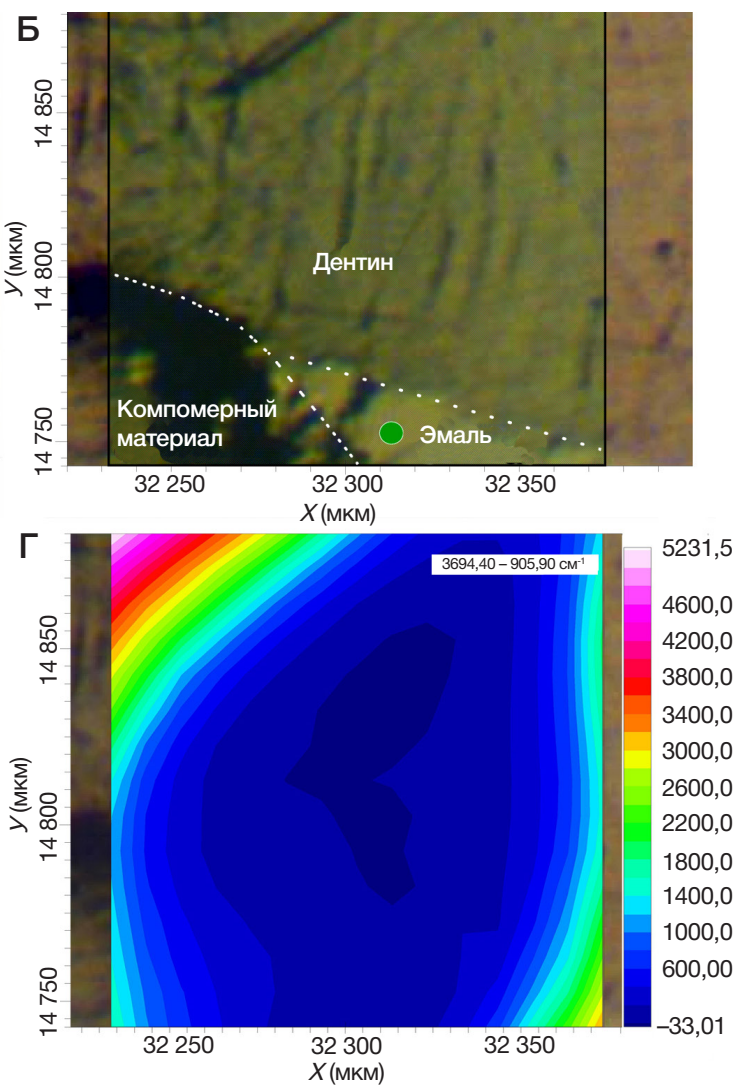


моды колебания данного диапазона принадлежат группам $\mathrm{CH}_{2}-\mathrm{CH}_{3}\left(1457 \mathrm{~cm}^{-1}\right)$ коллагена и амидным полосам (1650 $\mathrm{cm}^{-1}$ (Amid I - C=O), $1550 \mathrm{~cm}^{-1}$ (Amid II - N-H) и $1245 \mathrm{~cm}^{-1}$ (Amid III - CN stretching) [18, 19, 22]. Кроме этих полос в ИК-спектре присутствует мода в области $1725 \mathrm{~cm}^{-1}$, принадлежащая группе эсира $\left(-\mathrm{COOCH}_{3}\right)$, входящего в состав стоматологического материала на основе БИСГMA [19].

На рис. 2А представлена ИК-карта распределения молекулярной группы $\mathrm{PO}_{4}$ на участке интерфейса (рис. 1Б). Характерный ИК-спектр, представленный на рис. 2Б, был получен из участка образца на границе эмаль/биомиметический слой. В данном спектре содержится колебание группы $\mathrm{PO}_{4}$ в области 1163-981 см-1, присутствующей в составе апатита эмали/дентина зубов $[19,20]$ и биомиметическом материале. Исходя из полученных результатов можно заключить, что в области стоматологического материала не содержится фосфатных групп. Вся граничащая с эмалью область, где наблюдается ненулевая интенсивность активных колебаний спектра в диапазоне 1163-981 см-1, имеет размеры 30 мкм (рис. 3А, пунктирная линия).

Для получения дополнительной информации об участке с межфазной границей было сгенерировано ИК-изображение (рис. ЗА). Эта ИК-карта представляет информацию о распределении интенсивности молекулярных групп $\mathrm{CN}, \mathrm{NH}, \mathrm{C}=\mathrm{O}, \mathrm{CH}_{2} / \mathrm{CH}_{3}$ в области 1718-1358 см ${ }^{-1}$ (рис. 3Б), принадлежащих коллагену, а также компонентам Amid I и Amid II, относимых к органической составляющей
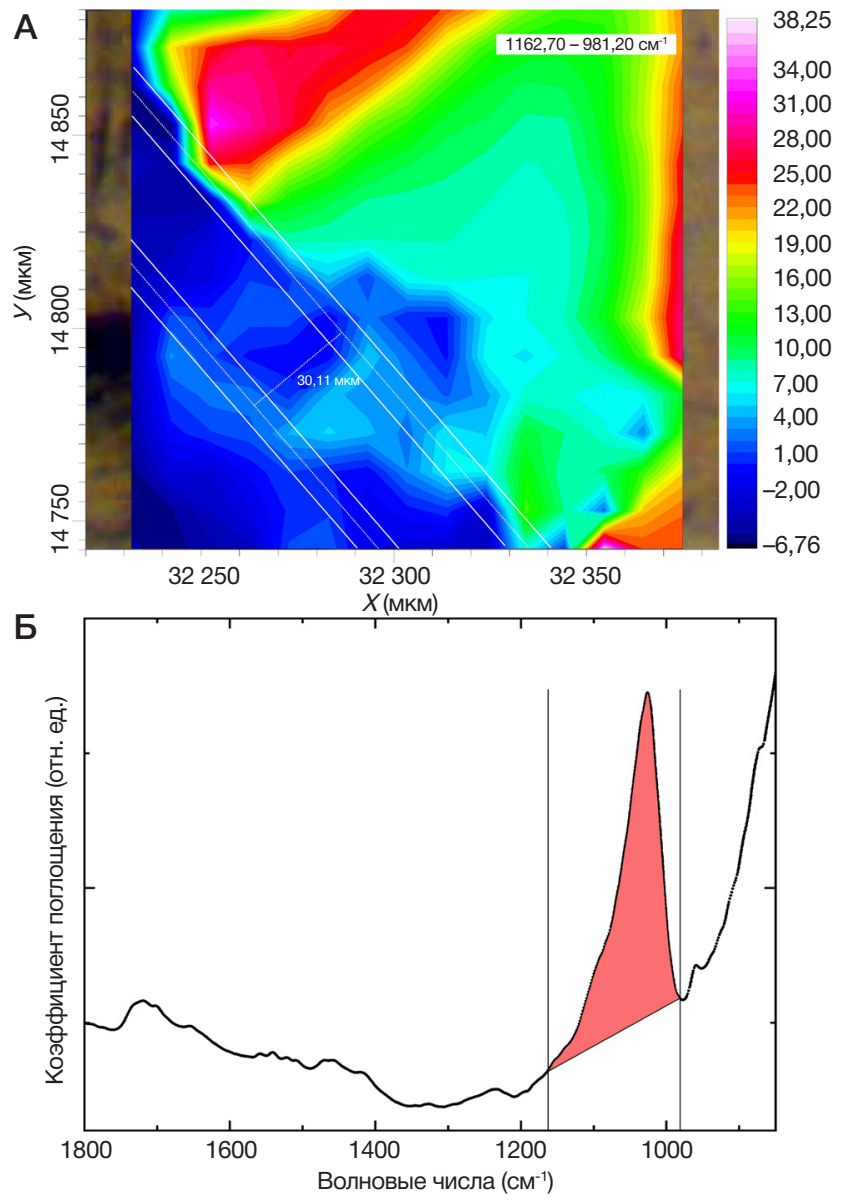

Рис. 2. А. ИК-карта поглощения, составленная на основе цветового кодирования интенсивности полосы спектра 1163-981 см-1. Б. ИК-спектр поглощения из области эмали образца, содержащий характерную фосфатную моду в области 1163-981 см-1 эмали/дентина и входящих в состав биомиметического буферного слоя.

Анализ данных, представленных на ИК-карте (рис. ЗА), позволяет предположить, что распределение органической составляющей в буферном биомиметическом слое по сравнению с распределением фосфатных групп более гомогенно. Эти данные согласуются с технологическими условиями подготовки образцов, а в частности с тем фактом, что в составе созданного биомиметического слоя доля гидроксиапатита меньше, чем доля органического компонента.

Как уже было отмечено, ИК-спектр, представленный на рис. 1В, содержит полосу поглощения, расположенную в области $1725 \mathrm{~cm}^{-1}$. Хорошо известно, что это колебание является характеристической особенностью ИК-спектров стоматологических цементов на основе БИС-ГМА и полиметилметакрилата и принадлежит молекулярной группе эфира $\left(-\mathrm{COOCH}_{3}\right)$ [19]. Более того, данная полоса поглощения не перекрывается с другими колебаниями, что позволяет построить ИК-изображение (рис. 4А) на ее основе (рис. 4Б).

Созданная ИК-карта показывает пространственное распределение стоматологического материала в анализируемой области (рис. 4А). На рисунке видно, что максимальное распределение интенсивности колебательной моды группы эфира $\left(-\mathrm{COOCH}_{3}\right)$ совпадает с наблюдаемым на оптическом снимке расположением материала (см. рис. 1Б).

Анализ полученного экспериментального спектра (см. рис. 1В) позволяет выделить интенсивную полосу

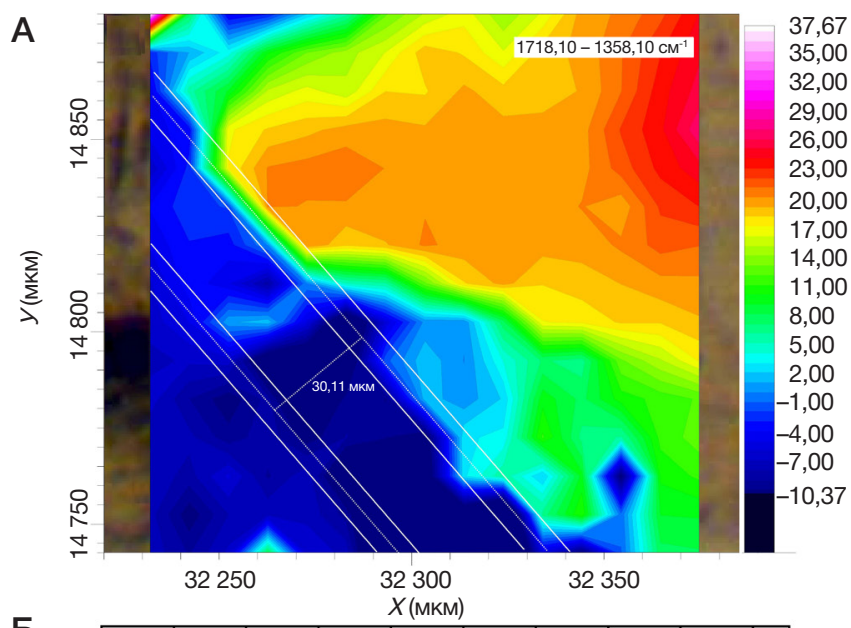

Б

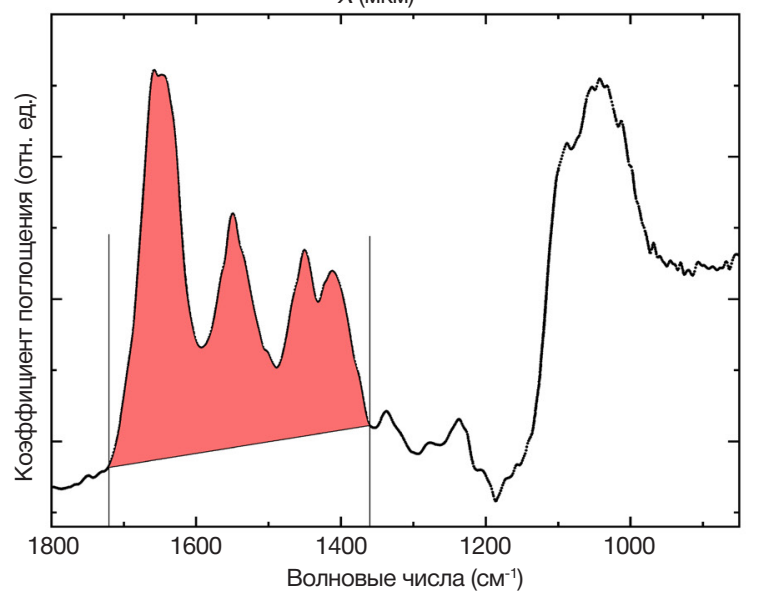

Рис. 3. А. ИК-карта поглощения, составленная на основе цветового кодирования интенсивности полосы спектра 1718-1358 см-1. Б. ИК-спектр поглощения, содержащий колебания молекулярных групп $\mathrm{CN}, \mathrm{NH}, \mathrm{C}=\mathrm{O}$, $\mathrm{CH}_{2} / \mathrm{CH}_{3}$ в области 1718-1358 $\mathrm{cm}^{-1}$ 
поглощения группы Amid III в области 1269-1224 см-1 и сформировать ИК-карту, относящуюся только к биомиметическому слою (рис. 5А). Следует отметить, что указанное колебание (рис. 5Б) не перекрывается с поглощением другими функциональными группами и может выступать реперной линией биомиметического композита.

Сопоставляя данные оптического изображения (см. рис. 1Б) и ИК-карты, представленной на рис. 5А, хорошо видно, что в основном молекулярная группа 1269-1224 см ${ }^{-1}$ распределена лишь в узкой области образца, содержащей интерфейс светоотверждаемый материал - биомиметический буферный слой - эмаль/дентин человеческого зуба.

\section{ОБСУЖДЕНИЕ РЕЗУЛЬТАТОВ}

Использование ИК-спектроскопии для исследования стоматологических материалов [19], биомиметических композитов [20], а также нативной ткани зубов человека [6] позволяет зачастую охарактеризовать молекулярный состав образцов лишь интегрально. В отличие от результатов указанных работ одномерные изображения (ИК-карты), полученные нами на основе цветового кодирования интенсивностей четырех основных спектральных полос (1752-1704 см-1, 1718-1358 см-1, 1269-1224 см ${ }^{-1}$, 1163-981 см-1), позволяют наглядно визуализировать распределение молекулярных групп на анализированном участке образца, а также установить молекулярно-химическое взаимодействие, происходящее

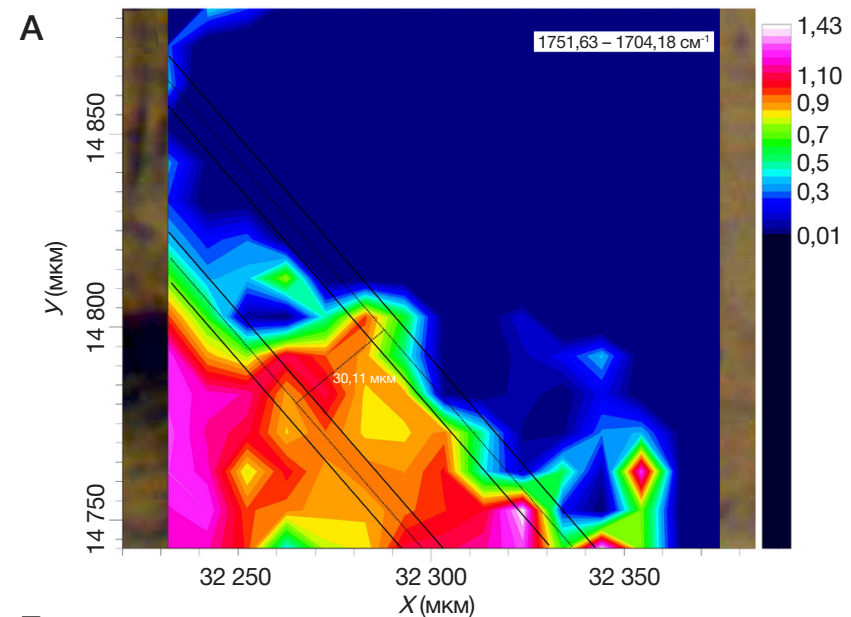

G

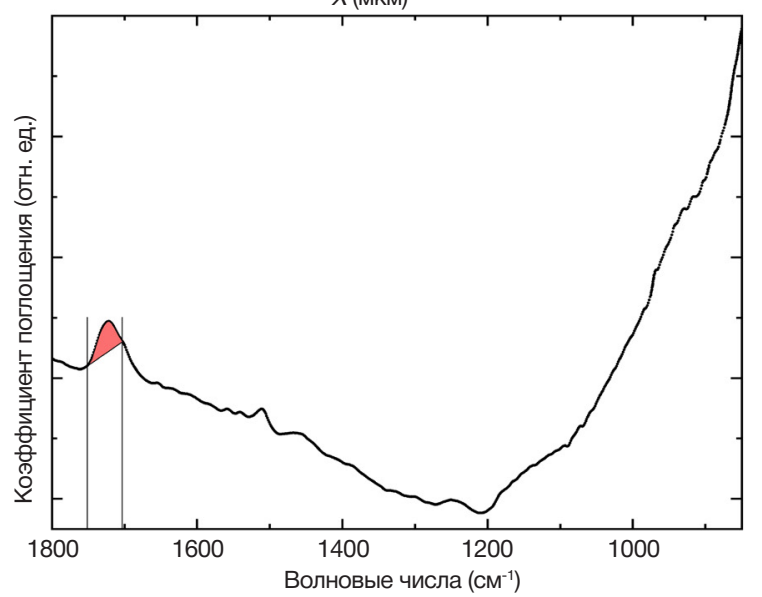

Рис. 4. А. ИК-карта поглощения, составленная на основе цветового кодирования интенсивности полосы спектра 1752-1704 см-1. Б. ИК-спектр поглощения колебательной моды группы эфира $\left(-\mathrm{COOCH}_{3}\right)$ в области 1752-1704 $\mathrm{CM}^{-1}$ на границе интерфейса светоотверждаемый материал биомиметический буферный слой - эмаль/дентин человеческого зуба.

Анализируя полученные нами ИК-изображения участка гетерофазной границы, следует отметить, что весьма интересным на ИК-карте фоссратной группы (см. рис. 2А) представляется участок, имеющий интенсивность от 1,0 до 7,0. Эта зона относится к биомиметическому переходному слою, содержащему синтезированный карбонат-замещенный гидроксиапатит кальция, включение которого в состав биомиметического слоя позволяет повысить его молекулярно-химическое сродство с анатомической основой зуба [20]. Благодаря включению КГАП в биомиметический слой на ИК-карте (см. рис. 2А) хорошо заметна межфазная граница только между биомиметическим слоем и стоматологическим материалом, где резкая градация по цвету определяется интенсивностью моды колебаний группы РО КГАП. При этом явно выраженный интерфейс нативная ткань биомиметический композит отсутствует, что подтверждает высокое сродство последнего с эмалью и дентином.

Следует, однако, отметить, что анализа только лишь ИКкарты, отображающей распределение фоссратной группы, недостаточно для исследования процессов интеграции стоматологического материала с эмалью/дентином зуба человека с применением переходного биомиметического слоя. В области 1163-981 см-1 могут перекрываться полосы поглощения фосфатных групп (см. рис. 2Б) с колебаниями силикатов алюминия или оксида кремния,

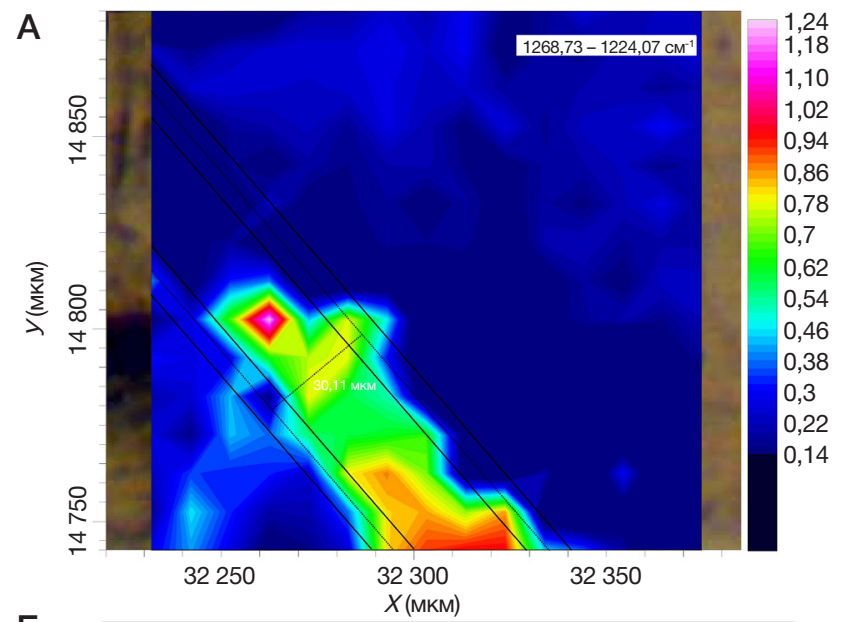

Б

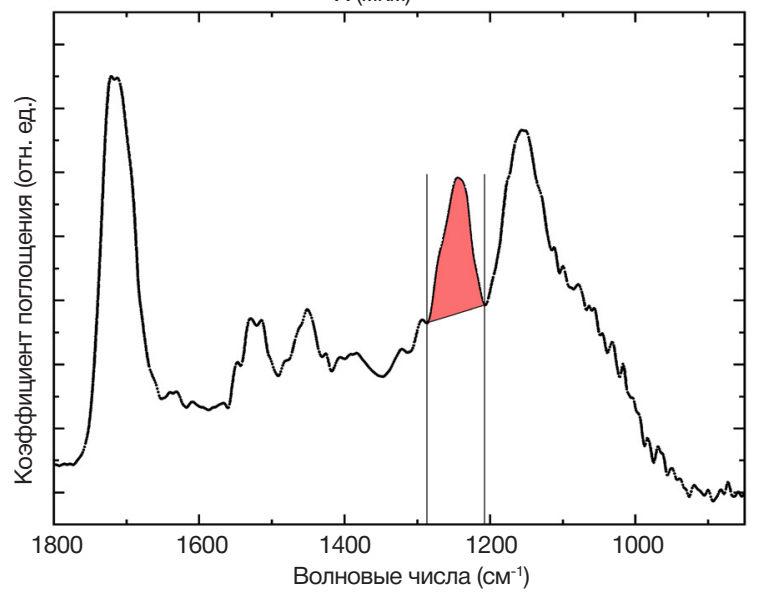

Рис. 5. А. ИК-карта поглощения, составленная на основе цветового кодирования интенсивности полосы Amid III в спектре 1269-1224 см-1. Б. ИК-спектр поглощения из области эмали образца, содержащий характерную фосфатную моду в области 1269-1224 см-1 
входящих в состав стоматологического материала [19, 25]. Однако рассмотрение границы интерфейса (см. рис. 1А и 2A) не выявляет значимого присутствия данных соединений в анализируемой области спектра (рис. 2Б), что может отвечать их низкой концентрации в выбранной для анализа области.

В дополнение к ИК-карте, отображающей распределение фосфатной группы, ИК-изображение распределения колебаний в области 1718-1358 см-1, соотносимых с органической составляющей образца (см. рис. 3А), позволяет пространственно более точно указать границу интерфейса между эмалью и дентином. Как видно из рис. ЗА, в области дентина характерно более высокое (красная область), по сравнению с эмалью (зеленая область), содержание органической составляющей, что соответствует известным данным [20].

В то же время, рассматривая вопрос о взаимодействии компомерного материала/биомиметического бусерного слоя и нативных твердых тканей необходимо обратить внимание на тот факт, что область колебаний 1718-1358 см-1 в ИК-спектре содержит целый ряд перекрывающихся полос [18]. Это создает трудности для интерпретации результатов и препятствует получению однозначных выводов о типе взаимодействия в области интерфейса.

В свою очередь анализ ИК-карт на основе распределения молекулярной группы эфира $\left(-\mathrm{COOCH}_{3}\right)$ (см. рис. 4A) и группы Amid III (рис. 5A), которые не имеют перекрывания с другими колебательными полосами в ИK-спектре, позволяет нам сделать следующие заключения o характере гетерофазной границы биомиметическая система/естественная твердая ткань. Во-первых, хорошо видно, что область интеграции стоматологического материала с участком эмали, где перепад интенсивности колебательной моды $-\mathrm{COOCH}_{3}$ от максимального до минимального, наблюдается на участке шириной 14 мкм и накладывается на зону, в которой в большей степени преобладает органическая составляющая (рис. 4А, 5А). Во-вторых, из анализа распределения интенсивности поглощения для группы Amid III (рис. 5A), присутствующей в составе биомиметического переходного слоя, следует, что внедренный биомиметический слой отделяет нативные твердые ткани от стоматологического материала.

Отметим, что все построенные ИК-изображения (см. рис. 2A, 3А, 4A, 5A) наглядно отображают границу переходного слоя, в то время как иные методы визуализации показывают морфологическую картину на границе стоматологический материал/эмаль/дентин зубов $[2,4,15]$, что не дает возможности анализировать переходные слои близкого состава в области интеграции.

Следует сказать, что одновременный анализ нескольких одномерных ИК-изображений молекулярных групп не всегда позволяет визуализировать взаимодействия, происходящие на гетерофазном интерфейсе между близкими по структуре материалами [6]. Это связано с ограничениями одномерного подхода к выявлению спектральных изменений при различении незначительных изменений в химической структуре. Однако неудобства могут быть преодолены за счет применения для анализа ИК-карт многомерных методов кластеризации, позволяющих эффективно систематизировать большое количество многокомпонентных ИК-спектров [26]. Используя этот подход, нам удалось проанализировать особенности сложного интерфейса стоматологический материал - биомиметический переходной слой эмаль - дентин зуба человека. Кластерный анализ, выполненный с учетом всех особенностей в спектральных областях 1752-1704 см-1, 1718-1358 см-1, 1269-1224 см-1, 1163-981 см-1, обнаруживает, что взаимодействие между стоматологическим материалом и нативной твердой тканью зуба происходит посредством буферного слоя (рис. 6, показано пунктиром).

Распределение молекулярно-химических групп фоссратов, протеинов, амидов и компонентов эфира (рис. 6) показывает, что биомиметический слой между эмалью и коммерческим материалом связывается с частично деминерализованным эмалевым матриксом посредством образующегося буферного переходного подслоя, что может указывать на возникновение органоминерального взаимодействия в анализируемой области. В то же время из анализа данных (см. рис. 6) видно, что переходная область между биомиметическим слоем и дентином значительно шире. Это следствие более пористой структуры у дентина, по сравнению с эмалью $[1,2]$. Что же касается формирования интерфейса между биомиметическим слоем и коммерческим стоматологическим материалом, то исходя из результатов кластеризации отчетливо видно, что существует тенденция проникновения органической и минеральной составляющих биомиметического буферного слоя в стоматологический светоотверждаемый адгезив с образованием переходного интерфейсного слоя.

Исходя из имеющихся данных можно предположить, что реальная величина переходного (интегрирующего) подслоя между биомиметическим композитом, стоматологическим
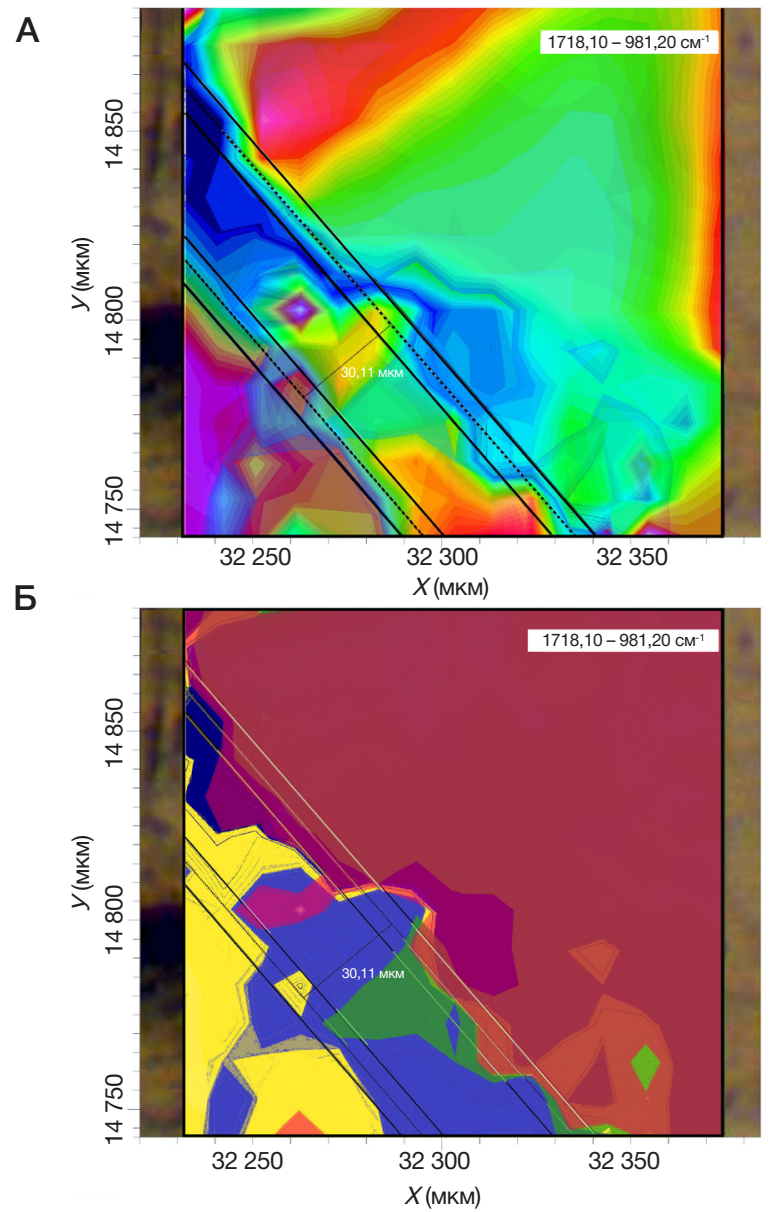

Рис. 6. Кластерный анализ, выполненный с учетом особенностей спектральных областей 1760-1690 см-1 и 1520-1360 см-1 с выделением области биомиметического композита 
материалом и твердой тканью зуба составляет 3-4 мкм, что согласуется с имеющимися научными представлениями [27].

Полученные на основе анализа всех ИК-изображений данные (см. рис. 2-6) доподлинно свидетельствуют о химической дифференциации функциональных групп всех материалов в области границы биомиметическая система/естественная твердая ткань и подтверждают эфффективность выбранного подхода для анализа интеграции стоматологических цементов и биомиметических композитов нового поколения.

Следует отметить, что полученные нами данные справедливы лишь в рамках примененной нами при создании образцов методики тотального протравливания. Однако эти результаты могут быть справедливы и для тех методик кондиционирования твердых тканей (самопротравливания, самоадгезивных систем и т. д.), в которых используют компоненты, подобные по химическому воздействию или составу материалам, исследованным нами в работе.

\section{ВЫВОДЫ}

Продемонстрирована возможность применения молекулярной многомерной ИК-визуализации для анализа интеграции нового поколения биомиметических материалов, воспроизводящих минералорганический комплекс эмали с нативными твердыми тканями зуба человека. С применением ИК-картирования интенсивности конкретной функциональной молекулярной группы с использованием синхротронного излучения были найдены и визуализированы различия между здоровой тканью, стоматологическим материалом и биомиметическим переходным слоем в межфазных областях, а также определены расположение и концентрация функциональных групп, отвечающих процессам интеграции биомиметического композита и нативной твердой ткани зуба человека. Показано, что разработанная нами биомиметическая система, на основе нанокристаллического КГАП, полученного из биогенного источника кальция и комплекса основных полярных аминокислот, соответствующих органоминеральному комплексу зубов человека, способна образовывать функциональную связь с твердой тканью зуба человека. Полученные нами микроспектроскопические данные достоверно подтверждают химическую диффференциацию материалов и наличие органоминерального взаимодействия на границе биомиметическая система/естественная твердая ткань.

\section{Литература}

1. Peutzfeldt A, Sahafi A, Flury S. Bonding of restorative materials to dentin with various luting agents. Oper Dent. 2011 Jun; 36 (3): 266-73.

2. Temel UB, Van Ende A, Van Meerbeek B, Ermis RB. Bond strength and cement-tooth interfacial characterization of self-adhesive composite cements. Am J Dent. 2017 Aug; 30 (4): 205-11.

3. Rohr N, Fischer J. Tooth surface treatment strategies for adhesive cementation. J Adv Prosthodont. 2017 Apr; 9 (2): 85-92.

4. Pontes DG, Araujo CTP, Prieto LT, de Oliveira DCRS, Coppini EK, Dias CTS, Paulillo LAMS. Nanoleakage of fiber posts luted with different adhesive strategies and the effect of chlorhexidine on the interface of dentin and self-adhesive cements. Gen Dent. 2015 Jun; 63 (3): 31-7.

5. Barandehfard F, Kianpour Rad M, Hosseinnia A, Khoshroo K, Tahriri M, Jazayeri HE, Moharamzadeh K, Tayebi L. The addition of synthesized hydroxyapatite and fluorapatite nanoparticles to a glass-ionomer cement for dental restoration and its effects on mechanical properties. Ceramics International. 2016 Nov 15; 42 (15): 17866-75.

6. Simon JC, A. Lucas S, Lee RC, Darling CL, Staninec M, Vaderhobli R, Pelzner R, Fried D. Near-infrared imaging of secondary caries lesions around composite restorations at wavelengths from 1300-1700-nm. Dental Materials. 2016 Apr 1; 32 (4): 587-95.

7. Uskoković $V$. Biomineralization and biomimicry of tooth enamel. In: Non-Metallic Biomaterials for Tooth Repair and Replacement [Internet]. Elsevier; 2013 [cited 2014 Sep 10]: 20-44. Available from: http://linkinghub.elsevier.com/retrieve/pii/ B9780857092441500021.

8. Niu L, Zhang W, Pashley DH, Breschi L, Mao J, Chen J, Tay FR. Biomimetic remineralization of dentin. Dental Materials. 2014; 30 (1): 77-96.

9. Cao C, Mei M, Li Q, Lo E, Chu C. Methods for Biomimetic Mineralisation of Human Enamel: A Systematic Review. Materials. 2015 May 26; 8 (6): 2873-86.

10. Dorozhkin SV. Hydroxyapatite and Other Calcium Orthophosphates: Bioceramics, Coatings and Dental Applications [Internet]. Nova Science Publishers, Inc New York; 2017 [cited 2017 Aug 23]. 462 p. Available from: https://istina.msu.ru/publications/ book/58538935/

11. El Rhilassi A, Mourabet M, Bennani-Ziatni M, El Hamri R, Taitai A.

Interaction of some essential amino acids with synthesized poorly crystalline hydroxyapatite. Journal of Saudi Chemical Society. 2016; 20 (Suppl 1): 632-40.

12. Li H, Gong M, Yang A, Ma J, Li X, Yan Y. Degradable biocomposite of nano calcium-deficient hydroxyapatite-multi (amino acid) copolymer. Int J Nanomedicine. 2012; (7): 1287-95.

13. Aljabo A, Abou Neel EA, Knowles JC, Young AM. Development of dental composites with reactive fillers that promote precipitation of antibacterial-hydroxyapatite layers. Materials Science and Engineering: C. 2016; (60): 285-92.

14. Tavafoghi M, Cerruti M. The role of amino acids in hydroxyapatite mineralization. Journal of The Royal Society Interface. 2016 Oct 1; 13 (123): 20160462.

15. Ruan Q, Zhang $Y$, Yang X, Nutt S, Moradian-Oldak J. An amelogenin-chitosan matrix promotes assembly of an enamellike layer with a dense interface. Acta Biomaterialia. 2013 Jul; 9 (7): 7289-97.

16. Baker MJ, Trevisan J, Bassan P, Bhargava R, Butler HJ, Dorling KM, et al. Using Fourier transform IR spectroscopy to analyze biological materials. Nat Protocols. 2014; 9 (8): 1771-91.

17. Vongsvivut J, Pérez-Guaita D, Wood BR, Heraud P, Khambatta K, Hartnell D, et al. Synchrotron macro ATR-FTIR microspectroscopy for high-resolution chemical mapping of single cells. Analyst. 2019 Mar 14; 144 (10): 3226-38.

18. Seredin P, Goloshchapov D, Ippolitov Y, Vongsvivut P. Pathologyspecific molecular profiles of saliva in patients with multiple dental caries - potential application for predictive, preventive and personalised medical services. EPMA Journal. 2018 Jun 1; 9 (2): 195-203.

19. Hędzelek W, Marcinkowska A, Domka L, Wachowiak R. Infrared Spectroscopic Identification of Chosen Dental Materials and Natural Teeth. Acta Physica Polonica A. 2008 Aug; 114 (2): 471-84.

20. Seredin PV, Goloshchapov DL, Prutskij T, Ippolitov YuA. Fabrication and characterisation of composites materials similar optically and in composition to native dental tissues. Results in Physics. 2017; (7): 1086-94.

21. Ерусалимов Ф. А., Ипполитов Ю. А., Кунин А. А. Биоактивная бондинговая система [интернет]. RU2423966C2, 2011 [cited 2019 May 20]. Доступно по ссылке: https://patents.google. com/patent/RU2423966C2/ru. 
22. Seredin PV, Goloshchapov DL, Gushchin MS, Ippolitov YA, Prutskij T. The importance of the biomimetic composites components for recreating the optical properties and molecular composition of intact dental tissues. J Phys: Conf Ser. 2017; 917 (4): 042019.

23. Ипполитов Ю. А. Возможность повышения биологической тропности светоотверждаемой бондинговой системы для адгезии твердых тканей зуба к пломбировочному материалу. Волгоградский научно-медицинский журнал. 2010; 4 (28): 31-4.

24. Середин П. В., Голощапов Д. Л., Prutskij Т., Ипполитов Ю. А. Единовременный анализ микрообластей кариозного дентина методами лазерно-индуцированной фрлуоресценции и рамановской спектромикроскопии. Оптика и спектроскопия. 2018; 125 (11): 708.

\section{References}

1. Peutzfeldt A, Sahafi A, Flury S. Bonding of restorative materials to dentin with various luting agents. Oper Dent. 2011 Jun; 36 (3): 266-73.

2. Temel UB, Van Ende A, Van Meerbeek B, Ermis RB. Bond strength and cement-tooth interfacial characterization of self-adhesive composite cements. Am J Dent. 2017 Aug; 30 (4): 205-11.

3. Rohr N, Fischer J. Tooth surface treatment strategies for adhesive cementation. J Adv Prosthodont. 2017 Apr; 9 (2): 85-92.

4. Pontes DG, Araujo CTP, Prieto LT, de Oliveira DCRS, Coppini EK, Dias CTS, Paulillo LAMS. Nanoleakage of fiber posts luted with different adhesive strategies and the effect of chlorhexidine on the interface of dentin and self-adhesive cements. Gen Dent. 2015 Jun; 63 (3): 31-7.

5. Barandehfard F, Kianpour Rad M, Hosseinnia A, Khoshroo K, Tahriri M, Jazayeri HE, Moharamzadeh K, Tayebi L. The addition of synthesized hydroxyapatite and fluorapatite nanoparticles to a glass-ionomer cement for dental restoration and its effects on mechanical properties. Ceramics International. 2016 Nov 15; 42 (15): 17866-75.

6. Simon JC, A. Lucas S, Lee RC, Darling CL, Staninec M, Vaderhobli R, Pelzner R, Fried D. Near-infrared imaging of secondary caries lesions around composite restorations at wavelengths from 1300-1700-nm. Dental Materials. 2016 Apr 1; 32 (4): 587-95.

7. Uskoković V. Biomineralization and biomimicry of tooth enamel. In: Non-Metallic Biomaterials for Tooth Repair and Replacement [Internet]. Elsevier; 2013 [cited 2014 Sep 10]: 20-44. Available from: http://linkinghub.elsevier.com/retrieve/pii/ B9780857092441500021.

8. Niu L, Zhang W, Pashley DH, Breschi L, Mao J, Chen J, Tay FR. Biomimetic remineralization of dentin. Dental Materials. 2014; 30 (1): 77-96.

9. Cao C, Mei M, Li Q, Lo E, Chu C. Methods for Biomimetic Mineralisation of Human Enamel: A Systematic Review. Materials. 2015 May 26; 8 (6): 2873-86.

10. Dorozhkin SV. Hydroxyapatite and Other Calcium Orthophosphates: Bioceramics, Coatings and Dental Applications [Internet]. Nova Science Publishers, Inc New York; 2017 [cited 2017 Aug 23]. 462 p. Available from: https://istina.msu.ru/publications/ book/58538935/

11. El Rhilassi A, Mourabet M, Bennani-Ziatni M, El Hamri R, Taitai A. Interaction of some essential amino acids with synthesized poorly crystalline hydroxyapatite. Journal of Saudi Chemical Society. 2016; 20 (Suppl 1): 632-40.

12. Li H, Gong M, Yang A, Ma J, Li X, Yan Y. Degradable biocomposite of nano calcium-deficient hydroxyapatite-multi(amino acid) copolymer. Int J Nanomedicine. 2012; (7): 1287-95.

13. Aljabo A, Abou Neel EA, Knowles JC, Young AM. Development of dental composites with reactive fillers that promote precipitation of antibacterial-hydroxyapatite layers. Materials Science and Engineering: C. 2016; (60): 285-92.

14. Tavafoghi M, Cerruti M. The role of amino acids in hydroxyapatite mineralization. Journal of The Royal Society Interface. 2016 Oct 1; 13 (123): 20160462
25. Khan AS, Khalid H, Sarfraz Z, Khan M, labal J, Muhammad N, et al. Vibrational spectroscopy of selective dental restorative materials. Applied Spectroscopy Reviews. 2017 Jul 3; 52 (6): $507-40$.

26. Kobrina Y, Rieppo L, Saarakkala S, Pulkkinen HJ, Tiitu V, Valonen P, et al. Cluster analysis of infrared spectra can differentiate intact and repaired articular cartilage. Osteoarthritis and Cartilage. 2013 Mar 1; 21 (3): 462-9.

27. Atmeh AR, Chong EZ, Richard G, Festy F, Watson TF. Dentin-cement Interfacial Interaction: Calcium Silicates and Polyalkenoates. Journal of Dental Research [Internet]. 2012 Mar 20 [cited 2018 Apr 13]; Available from: http://journals.sagepub. com/doi/abs/10.1177/0022034512443068.
15. Ruan $Q$, Zhang $Y$, Yang $X$, Nutt S, Moradian-Oldak J. An amelogenin-chitosan matrix promotes assembly of an enamellike layer with a dense interface. Acta Biomaterialia. 2013 Jul; 9 (7): 7289-97.

16. Baker MJ, Trevisan J, Bassan P, Bhargava R, Butler HJ, Dorling KM, et al. Using Fourier transform IR spectroscopy to analyze biological materials. Nat Protocols. 2014; 9 (8): 1771-91.

17. Vongsvivut J, Pérez-Guaita D, Wood BR, Heraud P, Khambatta K, Hartnell D, et al. Synchrotron macro ATR-FTIR microspectroscopy for high-resolution chemical mapping of single cells. Analyst. 2019 Mar 14; 144 (10): 3226-38.

18. Seredin P, Goloshchapov D, Ippolitov Y, Vongsvivut P. Pathologyspecific molecular profiles of saliva in patients with multiple dental caries - potential application for predictive, preventive and personalised medical services. EPMA Journal. 2018 Jun 1; 9 (2): 195-203.

19. Hedzelek W, Marcinkowska A, Domka L, Wachowiak R. Infrared Spectroscopic Identification of Chosen Dental Materials and Natural Teeth. Acta Physica Polonica A. 2008 Aug; 114 (2): 471-84.

20. Seredin PV, Goloshchapov DL, Prutskij T, Ippolitov YuA. Fabrication and characterisation of composites materials similar optically and in composition to native dental tissues. Results in Physics. 2017; (7): 1086-94

21. Erusalimov FA, Ippolitov YuA, Kunin AA. Bioactive bonding system [Internet]. RU2423966C2, 2011 [cited 2019 Jul 18]. Available from: https://patents.google.com/patent/RU2423966C2/en

22. Seredin PV, Goloshchapov DL, Gushchin MS, Ippolitov YA, Prutskij T. The importance of the biomimetic composites components for recreating the optical properties and molecular composition of intact dental tissues. J Phys: Conf Ser. 2017; 917 (4): 042019.

23. Ippolitov YuA. The possibility of bond system biological compatibility improvement for adhesion of hard dental tissues to filling material. Volgogradskij nauchno-medicinskij zhurnal. 2010; 4 (28): 31-4.

24. Seredin PV, Goloshchapov DL, Prutskij T, Ippolitov YuA. A Simultaneous Analysis of Microregions of Carious Dentin by the Methods of Laser-Induced Fluorescence and Raman Spectromicroscopy. Opt Spectrosc. 2018 Nov 1; 125 (5): 803-9.

25. Khan AS, Khalid H, Sarfraz Z, Khan M, Iqbal J, Muhammad N, et al. Vibrational spectroscopy of selective dental restorative materials. Applied Spectroscopy Reviews. 2017 Jul 3; 52 (6): $507-40$

26. Kobrina Y, Rieppo L, Saarakkala S, Pulkkinen HJ, Tiitu V, Valonen P, et al. Cluster analysis of infrared spectra can differentiate intact and repaired articular cartilage. Osteoarthritis and Cartilage. 2013 Mar 1; 21 (3): 462-9

27. Atmeh AR, Chong EZ, Richard G, Festy F, Watson TF. Dentin-cement Interfacial Interaction: Calcium Silicates and Polyalkenoates. Journal of Dental Research [Internet]. 2012 Mar 20 [cited 2018 Apr 13]; Available from: http://journals.sagepub. com/doi/abs/10.1177/0022034512443068 